\title{
CARACTERÍSTICAS SENSORIAIS DE LEITES DE SOJA RECONSTITUIIDOS1
}

\author{
SIN-HUEI WANG ${ }^{2}$, LAIR CHAVES CABRAL ${ }^{3}$, FLAVIA BATISTA ARAUJO ${ }^{4}$ e LUCIANA HELENA MAIA ${ }^{5}$
}

RESUMO - Foram estudadas a viscosidade aparente e as características sensoriais dos leites de soja reconstituídos, elaborados com leites de soja em pó submetidos previamente à homogeneização em diferentes pressões $(3.000,4.000,5.000$ e 6.000 psi). Verificou-se que a viscosidade aparente aumentou progressivamente com o aumento da pressão de homogeneização. As pressões de 4.000, 5.000 e 6.000 psi de homogeneização resultaram na obtenção de leites de soja reconstituídos de melhor aparência, sabor e textura, sendo os com sabores de baunilha e coco elaborados com leites de soja em pó submetidos previamente a pressões de 4.000 e 5.000 psi de homogeneização igualmente preferidos pela equipe massal de provadores não-treinados. Portanto, os melhores níveis de viscosidade aparente que se correlacionam com o corpo são 21 e 26 centipoises, ou seja, o uso de 4.000 e 5.000 psi na pressão de homogeneização, respectivamente.

Termos para indexação: pressão de homogeneização, viscosidade aparente, sabor, textura.

\section{SENSORY CHARACTERISTICS OF RECONSTITUTED SOYBEAN MILK}

\begin{abstract}
Sensory characteristics and apparent viscosity of reconstituted soybean milk obtained from powdered soybean milk submitted previously to different homogenization pressures $(3,000$, $4,000,5,000$ and $6,000 \mathrm{psi}$ ) were studied. It was observed that the apparent viscosity increased progressively with the increase of homogenization pressure. Pressures of 4,000, 5,000 and 6,000 psi of homogenization resulted in reconstituted products of better appearance, flavor and texture. Reconstituted soybean milks obtained from powdered soybean milk previously submitted to homogenization pressures of 4,000 and 5,000 psi, and flavored with vanilla and coconut, were equally preferred by consumer-type panelists. It was found that best levels of apparent viscosity which correlate with the best body are 21 and 26 centipoises, which correspond to homogenization pressures of 4,000 and 5,000 psi, respectively.
\end{abstract}

Index terms: homogenization pressures, apparent viscosity, flavor, texture.

\section{INTRODUÇÃO}

O leite de soja, por ser uma bebida protéica de baixo custo, de bom valor nutritivo e de fácil obtenção, representa importante alternativa para a nutrição humana em geral, particularmente nos lugares

\footnotetext{
${ }^{1}$ Aceito para publicação em 2 de julho de 1998.

${ }^{2}$ Bioquímica, Drẹ , Prof ${ }^{-}$Adjunta, Dep. Economia Doméstica, ICHS, UFRRJ, CEP 23851-970 Seropédica, RJ.

${ }^{3}$ Químico, Dr., Embrapa-Centro Nacional de Pesquisa de Tecnologia Agroindustrial de Alimentos (CTAA), Av. das Américas, 29501, CEP 23020-470 Guaratiba, RJ.

${ }^{4}$ Economista Doméstica, aluna de Pós-graduação da UFV, CEP 36570-000 Viçosa, MG.

${ }^{5}$ Economista Doméstica, aluna de Pós-graduação da UFRRJ
}

onde o leite bovino é caro ou indisponível. Sua importância se torna ainda mais evidente, uma vez que pode ser usado por pessoas alérgicas à lactose e proteína presentes no leite bovino (Darunee et al., 1976).

Entretanto, a aceitação do leite de soja tem sido limitada, devido ao sabor de feijão cru (beany flavor) causado pela atividade da lipoxigenase durante o rompimento do grão de soja (Wilkens et al., 1967; Mattick \& Hand, 1969; Bourne, 1970; Nelson et al., 1971). Numerosas tentativas têm sido feitas com a finalidade de melhorar o sabor (Hand et al., 1964; Wilkens et al., 1967; Badenhop \& Hackler, 1970; Khaleque et al., 1970; Kon et al., 1970; Nelson et al., 1976; Omosaiye \& Cheryan, 1979). Dentre estas, destacam-se: (a) moagem do grão com água quente a 
$80-100^{\circ} \mathrm{C}$ (Wilkens et al., 1967); (b) branqueamento (Nelson et al., 1976); (c) moagem do grão em baixo pH seguido de cozimento (Kon et al., 1970); e (d) maceração do grão em meio alcalino (Badenhop \& Hackler, 1970). Os produtos obtidos por estes processos tem melhor sabor, porém, pode ocorrer, em alguns casos, a perda de solubilidade das proteínas, diminuindo a sua extratibilidade.

Um processo utilizado por Nelson et al. (1976), que se baseou no branqueamento do grão de soja e posterior desintegração com água e homogeneização à alta pressão $\left(3.500 \mathrm{psi}\right.$ a $\left.200^{\circ} \mathrm{F}\right)$, tem alcançado sucesso na obtenção do leite de soja com sabor suave e boa solubilidade. O branqueamento do grão de soja favorece a inativação da lipoxigenase e do inibidor de tripsina, enquanto a homogeneização à alta pressão maximiza a solubilização de proteína. Os mesmos autores constataram ainda que a viscosidade do leite de soja está relacionada com a sensação da boca nas avaliações organolépticas, sendo que ela poderia ser afetada por variáveis do processo.

A obtenção do leite de soja em pó com sabor suave e alto teor de proteína constitui uma boa alternativa, porque permite uma vida de prateleira mais longa.

O presente trabalho foi realizado com o objetivo de estudar as características sensoriais dos leites de soja reconstituídos, elaborados com leites de soja em pó submetidos à homogeneização em diferentes pressões, antes de sua secagem por atomização, verificando suas correlações com o comportamento de viscosidade aparente.

\section{MATERIAL E MÉTODOS}

\section{Matéria-prima}

A matéria-prima usada para o presente estudo foi a soja Glycyne max (L.) Merrill, variedade BR-16, safra 19951996, fornecida pela Embrapa - Serviço de Produção de Sementes Básicas (SPSB) (Ponta Grossa, PR).

\section{Obtenção do leite de soja em pó}

Os grãos de soja foram decorticados usando-se o descascador mecânico de grãos. Os grãos decorticados foram branqueados em solução de $\mathrm{NaHCO}_{3}$ a $0,25 \%$ na proporção de 1:3 de soja:solução, durante 20 minutos. Em seguida, a solução de branqueamento foi drenada e os grãos foram desintegrados com água em ebulição, em moinho de facas e martelos, marca Treu S.A. (№ 63.202), com peneira de $0,5 \mathrm{~mm}$. A mistura resultante, com aproximadamente $11 \%$ de sólidos, foi submetida, por duas vezes, à homogeneização em homogeneizador APV Gaulin, modelo $15 \mathrm{MR}$, a $70^{\circ} \mathrm{C}$ e a pressões de $3.000,4.000,5.000 \mathrm{e}$ 6.000 psi, designados como A, B, C e D, respectivamente. Os leites de soja assim obtidos foram secados por atomização com temperatura de entrada e saída de $200^{\circ} \mathrm{C}$ e $90^{\circ} \mathrm{C}$, respectivamente, tendo como produtos finais leites de soja em pó A, B, C e D.

\section{Composição centesimal aproximada}

Umidade, extrato etéreo, proteína bruta e cinza foram determinadas segundo a American Association of Cereal Chemists (1969), e a fibra crua, de acordo com Van de Kamer \& Van Ginkel (1952). Carboidrato foi obtido por diferença.

\section{Atividade do inibidor de tripsina}

Determinou-se a atividade do inibidor de tripsina, de acordo com o método original de Kunitz, conforme descrito por Kakade et al. (1969).

\section{Viscosidade aparente do leite de soja reconstituído}

Os quatro leites respectivos de soja em pó foram reconstituídos em água, na proporção de 1:12 de soja:água, e submetidos à determinação de viscosidade aparente (centipoise) a $20^{\circ} \mathrm{C}$, usando-se reômetro de cilindros concêntricos da marca Contraves (modelo Rheomat - 30), acoplado ao programador (Rheoscan 100), banho termostático (Rheotherm 115), sistema de medição MSO e registrador gráfico da marca Rikadenki. As amostras foram submetidas a uma rampa de taxa de deformação, que variava linearmente de 23 a $1.730 \mathrm{~s}^{-1}$, com taxas de deformação crescentes durante 4 minutos (tempo de rampa), e taxas de deformação decrescentes em mais de 4 minutos. A viscosidade aparente foi determinada numa taxa de deformação fixa $\left(100 \mathrm{~s}^{-1}\right)$, que ofereceu melhor resultado.

\section{Avaliação sensorial do leite de soja reconstituído}

Antes da avaliação sensorial, os provadores foram selecionados pela sua capacidade de detectar diferenças. A seleção foi feita com teste triangular, usando-se leites de soja resconstituídos em estudo. Por meio da análise seqüencial, foram selecionados dez provadores, os quais foram treinados, a seguir, durante dez semanas, com as 
mesmas amostras, usando-se leite de soja cru como controle. Sessões preliminares foram feitas para explicar o que constituía uma boa qualidade. Os critérios observados no tocante a aparência foram: cor, e separação de fases; quanto a sabor: sabor de feijão cru, adstringência e amargor; e quanto a corpo: adesividade, recobrimento na boca e sensação na boca.

Os quatro leites respectivos de soja reconstituídos (1:12 de soja:água) foram submetidos a teste sensorial de qualidade (aparência, sabor e corpo), usando-se a Escala Estruturada de 9 pontos $(1$ = extremamente ruim; $9=$ excelente) e uma equipe de dez provadores treinados, de ambos os sexos.

Os leites de soja puros $(35 \mathrm{~mL})$ foram oferecidos, à temperatura ambiente, aos provadores, usando-se copinho de café descartável. Em cada sessão, dois leites de soja foram ordenados e devidamente codificados, e apresentados ao acaso aos provadores. Foram usadas seis sessões, com três repetições em cada amostra.

Das amostras avaliadas, foram selecionadas as três amostras que apresentaram melhores escores na aparência, sabor e corpo, sendo estas formuladas com açúcar $(5 \%)$, sal $(0,2 \%)$ e saborizante $(0,6 \%$, baunilha ou coco) para serem submetidas posteriormente ao teste massal de preferência. Foram usadas a Escala Hedônica de 9 pontos ( 1 = desgostei muitíssimo; 9 = gostei muitíssimo $)$ e uma equipe de 120 provadores não-treinados.

Os três leites de soja formulados com sabor de baunilha foram devidamente codificados, e apresentados ordenadamente ao acaso aos provadores. $\mathrm{O}$ mesmo procedimento foi realizado no tocante aos leites de soja saborizados com coco.

\section{Análise estatística}

Quanto aos resultados de determinações de composição química e atividade do inibidor de tripsina, usou-se delineamento inteiramente casualizado, em que foram feitas análises de variância, com posterior comparação das diferenças entre as médias pelo teste de Tukey a 1\% de probabilidade. Foi feita triplicata para cada determinação.

Foi usado delineamento em blocos incompletos, com três repetições (plan 11.1) para testes sensoriais de qualidade (aparência, sabor e corpo) em quatro amostras, e delineamento inteiramente casualizado para os sensoriais de preferência com três amostras, segundo Cochran \& Cox (1957). Foram feitas análises de variância com comparação de médias pelo teste de Tukey a $5 \%$ de probabilidade.

Determinou-se a equação de regressão a $1 \%$ de probabilidade quanto à viscosidade aparente, que foi feita em triplicata.
As análises estatísticas foram realizadas segundo os métodos descritos por Pimentel-Gomes (1982).

\section{RESULTADOS E DISCUSSÃO}

Na Tabela 1, observa-se que a soja decorticada mostrou teores de proteína e extrato etéreo maiores do que os da soja integral, o que indica que a casca da soja contém maiores teores de cinza e fibra.

A composição centesimal aproximada dos leites de soja em pó submetidos previamente à homogeneização em diferentes pressões está apresentada na Tabela 2. Exceto no tocante à umidade, não foram verificadas diferenças significativas entre as diferentes amostras, o que mostra que diferentes pressões de homogeneização não afetam os teores de proteína, extrato etéreo, cinza, fibra crua e carboidrato do leite de soja em pó. A variação dos teores de umidade se deve, provavelmente, à umidade relativa do ar onde as amostras se encontravam.

Não houve atividade residual do inibidor de tripsina nos leites de soja em pó estudados, o que indica que o branqueamento da soja em solução de $\mathrm{NaHCO}_{3}$ a $0,25 \%$ durante 20 minutos, utilizado no seu preparo, foi o suficiente para inativar completamente o inibidor de tripsina. Resultado semelhante foi verificado por Soetrisno et al. (1982), os quais constataram uma inativação total do inibidor de tripsina na soja submetida a aquecimento em água fervente por 20 minutos.

A Fig. 1 mostra a viscosidade aparente dos leites de soja reconstituídos, elaborados com leites de soja em pó submetidos à homogeneização em diferentes

TABELA 1. Composição centesimal aproximada (\% base seca) dos grãos de soja integral e decorticada.

\begin{tabular}{lcc}
\hline Composição & Soja integral & Soja decorticada \\
\hline Proteína (\%) & 40,03 & 42,41 \\
Extrato etéreo (\%) & 22,93 & 25,03 \\
Cinza (\%) & 5,24 & 4,80 \\
Fibra crua (\%) & 5,85 & 1,83 \\
Carboidrato $1 \%)$ & 25,95 & 25,93 \\
\hline
\end{tabular}

1 Calculado por diferença. 
TABELA 2. Composição centesimal aproximada (\% base úmida) dos leites de soja em pó submetidos previamente à homogeneização em diferentes pressões ${ }^{1}$.

\begin{tabular}{lccccccc}
\hline $\begin{array}{l}\text { Pressão de } \\
\text { homogeneização }(\mathrm{psi})\end{array}$ & $\begin{array}{c}\text { Leite de soja } \\
\text { em pó }\end{array}$ & $\begin{array}{c}\text { Umidade } \\
(\%)\end{array}$ & $\begin{array}{c}\text { Proteína } \\
(\%)\end{array}$ & $\begin{array}{c}\text { Extrato etéreo } \\
(\%)\end{array}$ & $\begin{array}{c}\text { Cinza } \\
(\%)\end{array}$ & $\begin{array}{c}\text { Fibra crua } \\
(\%)\end{array}$ & $\begin{array}{c}\text { Carboidrato }^{2} \\
(\%)\end{array}$ \\
\hline 3.000 & A & $2,86 \mathrm{a}$ & 45,36 & 26,24 & 4,70 & 2,39 & 18,45 \\
4.000 & $\mathrm{~B}$ & $2,59 \mathrm{~b}$ & 45,21 & 26,73 & 5,06 & 2,24 & 18,17 \\
5.000 & $\mathrm{C}$ & $2,95 \mathrm{a}$ & 44,75 & 26,43 & 4,80 & 2,27 & 18,83 \\
6.000 & $\mathrm{D}$ & $2,96 \mathrm{a}$ & 44,71 & 25,73 & 5,05 & 2,42 & 19,13 \\
\hline DMS & & 0,18 & - & - & - & - & - \\
CV $(\%)$ & & 0,96 & 0,91 & 4,51 & 5,94 & 8,05 & 2,36 \\
\hline
\end{tabular}

1 As médias seguidas de letras diferentes diferem estatisticamente entre si pelo teste de Tukey a $1 \%$ de probabilidade.

2 Calculado por diferença.

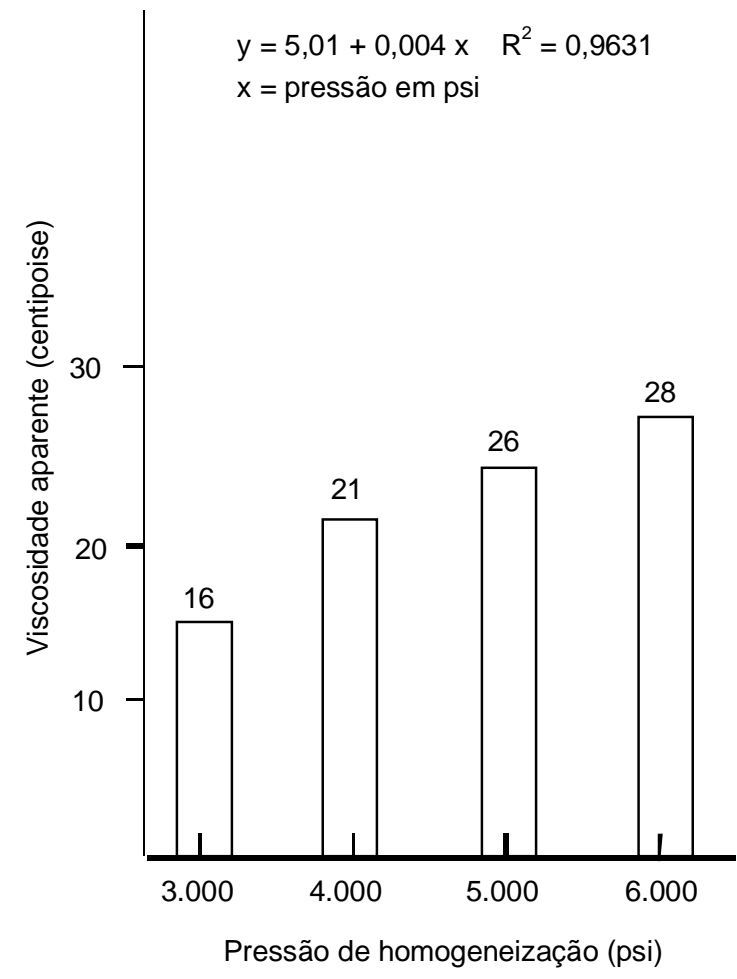

FIG. 1. Viscosidade aparente $\left(t^{0}=20^{\circ} \mathrm{C} ; \gamma=100 \mathrm{~s}^{-1}\right)$ dos leites de soja reconstituídos, elaborados com leites de soja em pó submetidos previamente à homogeneização em diferentes pressões. pressões $(3.000,4.000,5.000$ e 6.000 psi), antes de sua secagem por atomização. Verifica-se que houve um aumento linear da viscosidade aparente com o aumento da pressão de homogeneização.

De acordo com Cheftel et al. (1989), as forças de corte resultantes do aumento da pressão de homogeneização, além de fragmentarem proteínas em pequenas partículas, desnaturam a proteína pelo rompimento das interações não covalentes, causando desenrolamento das partículas de proteína, o que por conseqüência, resulta num aumento na viscosidade.

Os resultados obtidos na avaliação sensorial de aparência, sabor e corpo estão apresentados na Tabela 3. Diferenças não significativas foram observadas quanto à aparência dos leites de soja reconstituídos, elaborados com leites de soja em pó submetidos previamente à homogeneização em diferentes pressões. No entanto, os escores de avaliação do sabor foram aumentados com o aumento da pressão de homogeneização. Por outro lado, o aumento da pressão de homogeneização melhorou o corpo do leite de soja reconstituído até 5.000 psi, além da qual observa-se um decréscimo.

Johnson \& Snyder (1978) constataram que a homogeneização é útil para re-dispersar a proteína, que antes era coagulada pelo calor nos corpos protéicos durante o branqueamento do grão de soja. O aumento da pressão de homogeneização diminui o 
tamanho das partículas de lipídio, o que melhora a emulsificação do leite de soja.

Aminlari et al. (1977) reportaram que o aumento da pressão de homogeneização reduz o tamanho das partículas do leite de soja e as menores partículas teriam produzido menores gotículas durante sua secagem por atomização. Menores gotículas devem se secar mais rapidamente, sem que necessitem de muito calor, tornando-se, portanto, mais solúveis. Entretanto, ocorrerá o efeito adverso sobre a proteína de soja quando a pressão de homogeneização for muito alta.

Acredita-se, desta forma, que o sabor do leite de soja reconstituído esteja relacionado com a sua emulsificação. Um aumento na pressão de homogeneização melhora a emulsificação do leite de soja, tanto na sua forma líquida como em pó. Em conseqüência disso, o sabor do leite de soja reconstituído é melhorado. Já quanto a corpo, não basta uma boa emulsificação: é necessária também uma boa solubilidade, de modo que seja percebida uma sensação agradável.

Os melhores níveis de viscosidade aparente que correlacionam com o melhor corpo medido na avaliação sensorial correspondem a 21 e 26 centipoises, ou seja, o uso de 4.000 e 5.000 psi, respectivamente, na pressão de homogeneização aplicada a leite de soja, antes de sua secagem por atomização (Fig. 1 e Tabela 3). Estes resultados mostram que nem sempre

TABELA 3. Escores de avaliação sensorial de aparência, sabor e corpo para leites de soja reconstituídos, elaborados com leites de soja em pó submetidos previamente à homogeneização em diferentes pressões ${ }^{1}$.

\begin{tabular}{lcccc}
\hline $\begin{array}{l}\text { Pressão de homo- } \\
\text { geneização (psi) }\end{array}$ & $\begin{array}{l}\text { Leite de soja } \\
\text { reconstituído }\end{array}$ & Aparência & Sabor & Corpo \\
\hline 3.000 & A & $7,72 \mathrm{a}$ & $7,69 \mathrm{~b}$ & $7,69 \mathrm{~b}$ \\
4.000 & $\mathrm{~B}$ & $8,09 \mathrm{a}$ & $7,79 \mathrm{~b}$ & $8,14 \mathrm{a}$ \\
5.000 & $\mathrm{C}$ & $8,12 \mathrm{a}$ & $8,02 \mathrm{~b}$ & $8,04 \mathrm{a}$ \\
6.000 & $\mathrm{D}$ & $7,74 \mathrm{a}$ & $8,57 \mathrm{a}$ & $7,79 \mathrm{~b}$ \\
\hline DMS & & 0,42 & 0,34 & 0,16 \\
CV (\%) & & 1,59 & 1,08 & 0,52 \\
\hline
\end{tabular}

1 As médias seguidas de letras diferentes diferem estatisticamente entre si pelo teste de Tukey a $5 \%$ de probabilidade. a avaliação sensorial de corpo (subjetiva) se correlaciona bem com aquela feita com método instrumental (reômetro) de avaliação de viscosidade (objetiva). Somente em determinados valores de viscosidade aparente, os leites de soja reconstituídos apresentam os seus melhores escores de corpo na avaliação sensorial. A avaliação sensorial é, em alguns casos, mais importante do que a avaliação instrumental.

Considerando-se que sabor e corpo são atributos sensoriais exigidos para uma boa aceitabilidade do leite de soja, foram selecionadas apenas três amostras que tiveram os maiores escores de sabor e corpo (Tabela 3) para serem submetidas ao teste massal de preferência (Tabela 4). Os dados mostram que os leites de soja reconstituídos $\mathrm{B}$ e C (com sabores de baunilha e coco), elaborados com leites de soja em pó submetidos previamente à homogeneização de 4.000 e 5.000 psi, respectivamente, foram os mais apreciados, não havendo diferença entre eles. Estes resultados sugerem que o corpo seja um atributo sensorial que determina a preferência pelos leites de soja reconstituídos.

Resultados semelhantes foram encontrados por Nelson et al. (1976), os quais afirmaram que altas pressões de homogeneização são desejáveis para se obter boa sensação na boca em produtos acabados, porém, um excesso na pressão de homogeneização mostra desvantagens práticas, do ponto de vista do processo.

TABELA 4. Preferência pelos leites de soja reconstituídos, elaborados com leites de soja em pó submetidos previamente à homogeneização em diferentes pressões ${ }^{1}$.

\begin{tabular}{lccc}
\hline $\begin{array}{l}\text { Pressão de } \\
\text { homogeneização } \\
\text { (psi) }\end{array}$ & $\begin{array}{l}\text { Leite de soja } \\
\text { reconstituído }\end{array}$ & $\begin{array}{c}\text { Sabor de } \\
\text { baunilha }\end{array}$ & $\begin{array}{c}\text { Sabor de } \\
\text { coco }\end{array}$ \\
\hline 4.000 & $\mathrm{~B}$ & $8,07 \mathrm{ab}$ & $8,04 \mathrm{a}$ \\
5.000 & $\mathrm{C}$ & $8,36 \mathrm{a}$ & $8,16 \mathrm{a}$ \\
6.000 & $\mathrm{D}$ & $7,93 \mathrm{~b}$ & $7,33 \mathrm{~b}$ \\
\hline DMS & & 0,35 & 0,39 \\
$\mathrm{CV}(\%)$ & 4,24 & 4,97 \\
\hline 1 & &
\end{tabular}

Pesq. agropec. bras., Brasília, v.34, n.3, p.467-472, mar. 1999 


\section{CONCLUSÃo}

A homogeneização de 4.000 e 5.000 psi, respectivamente, utilizada para leites de soja, antes de sua secagem por atomização, resulta no melhor corpo de seus leites de soja reconstituídos, tendo preferência muito boa pela equipe massal de provadores nãotreinados.

\section{REFERÊNCIAS}

AMERICAN ASSOCIATION OF CEREAL CHEMISTS. Approved methods of the American Association of Cereal Chemists. 7.ed. Saint Paul, 1969. $2 \mathrm{v}$.

AMINLARI, M.; FERRIER, L.K.; NELSON, A.I. Protein dispersibility of spray-dried whole soybean milk base; effect of processing variables. Journal of Food Science, Chicago, v.42, n.4, p.985-988, 1977.

BADENHOP, A.F.; HACKLER, L.R. Effects of soaking soybeans in sodium hydroxide solution as pretreatment for soymilk production. Cereal Science Today, Saint Paul, v.15, n.3, p.84-88, 1970.

BOURNE, M.C. Recent advances in soybean milk processing technology. Protein Advisory Group Bulletin, New York, v.10, p.14-21, 1970.

CHEFTEL, J.C.; CUQ, J.L.; LORIENT, D. Proteínas alimentarias. Zaragoza: Acribia, 1989. 346p.

COCHRAN, W.G.; COX, G.M. Experimental designs. 2.ed. New York: John Wiley, 1957. 611p.

DARUNEE, T.; TANAKA, M.; CHICHESTER, C.O.; LEE, T.C. Degradation of raffinose and stachyose in soybean milk by alfa-galactosidase from Mortierella vinacea; entrapment of alfa-galactosidase within polyacrylamide gel. Journal of Food Science, Chicago, v.41, n.1, p.173-175, 1976

HAND, D.B.; STEINKRAUS, K.H.; VAN BUREN, J.P.; HACKLER, L.R.; ELRAWI, I.; PALLESEN, H.R. Pilot-plant studies on soymilk. Food Technology, Chicago, v.18, n.8, p.139-142, 1964.

JOHNSON, K.W.; SNYDER, H.E. Soymilk: a comparison of processing methods on yields and composition. Journal of Food Science, Chicago, v.43, n.2, p.349353,1978
KAKADE, M.L.; SIMONS, N.R.; LIENER, I.E. An evaluation of natural vs. synthetic substrates for measuring the antitrytic activity of soybean samples. Cereal Chemistry, Saint Paul, v.46, n.5, p.518-526, 1969.

KHALEQUE, A.; BANNATYNE, W.R.; WALLACE, G.M. Studies on the processing and properties of soymilk. I. Effect of preprocessing conditions on the flavour and compositions of soymilks. Journal of the Science of Food and Agriculture, London, v.21, n.11, p.579-583, 1970.

KON, S.; WAGNER, J.R.; GUADAGNI, D.G.; HORVAT, R.J. $\mathrm{pH}$ adjustment control of oxidative off-flavors during grinding of raw legume seeds. Journal of Food Science, Chicago, v.35, n.4, p.343-345, 1970.

MATTICK, L.R.; HAND, D.B. Identification of a volatile component in soybeans that contributes to the raw bean flavor. Journal of Agricultural and Food Chemistry, Washington, v.17, n.1, p.15-17, 1969.

NELSON, A.I.; STEINBERG, M.P.; WEI, L.S. Illinois process for preparation of soymilk. Journal of Food Science, Chicago, v.41, n.1, p.57-61, 1976.

NELSON, A.I.; WEI, L.S.; STEINBERG, M.P. Food products from whole soybeans. Soybean Digest, Hudson, v.31, n.3, p.32-34, 1971.

OMOSAIYE, O.; CHERYAN, M. Ultrafiltration of soybean water extracts: processing characteristics and yields. Journal of Food Science, Chicago, v.44, n.4, p.1027-1031, 1979.

PIMENTEL-GOMES, F. Curso de Estatística Experimental. 10.ed. São Paulo: Nobel, 1982. 430p.

SOETRISNO, U.; HOLMES, Z.A.; MILLER, L.T. Effect of heating times of soybean on vitamin B6 and folacin retention, trypsin inhibitor activity, and microstructure changes. Journal of Food Science, Chicago, v.47, n.2, p.530-534 and 537, 1982.

VAN DE KAMER, J.H.; VAN GINKEL, L. Rapid determination of crude fiber in cereals. Cereal Chemistry, Saint Paul, v.29, n.4, p.239-251, 1952.

WILKENS, W.F.; MATTICK, L.R.; HAND, D.B. Effect of processing method on oxidative offflavors of soybean milk. Food Technology, Chicago, v.21, n.12, p.1630-1633, 1967. 